17 Elstein AS, Bordage G. In: Dowie J, Elstein A, eds. Professional judgement; $a$ reader in clinical decision making. Cambridge: Cambridge University Press, 1988:109-29.

18 Barrows HS, Norman GR, Neufeld VR, Feightner JW. The clinical reasoning of randomly selected physicians in general medical practice. Clin Invest Med 1982;5:49-55.

19 Gill PW, Leaper DJ, Guillou PJ, et al. Observer variation in clinical diagnosis - a computer-aided assessment of its magnitude and importance in 552 patients with abdominal pain. Methods of Information in Medicine 1973;12:108-13.

20 Anonymous. Diagnosis: logic and psycho-logic [Editorial]. Lancet 1987;i: 840-1.

21 Schwartz WB. Decision analysis - a look at the chief complaints. N Engl f Med 1979;300:556-9.

22 Kassirer P. Teaching clinical medicine by iterative hypothesis testing; let's preach what we practice. N Engl F Med 1983;309:921-3.
23 Leaper DJ, Gill PW, Staniland JR, et al. Clinical diagnostic process; an analysis. Br.Med f 1973;ii:569-73.

24 Macartney FJ. Diagnostic logic. Br Med f 1987;295:1325-31.

25 Hoffbrand BI. Diagnosis and decisions - can we do better? Postgrad Med f 1987;63:729-30.

26 Wright HJ, Macadam DB. Clinical thinking and practice: diagnosis and decision in patient care. Edinburgh: Churchill Livingstone, 1983:69.

27 Balint M. The doctor, his patient and the illness. 2nd ed. Edinburgh: Churchill Livingstone, 1964

28 Hoffbrand BI. Diagnostic process. Lancet 1987;i 278-9.

29 Hampton JR, Harrison MJG, Mitchell JRA, et al., Relative contributions of history-taking, physical examination, and laboratory investigation to diagnosis and management of medical outpatients. Br.Med f 1975;ii:486-9.

(Accepted 28 December 1988)
This article and the one that follows it by William Laing are the seventh and eighth in a series of articles on the white paper Working for Patients and its accompanying working papers. The series started on 18 February (p 437) with another article by Ray Robinson.

\title{
NHS Review
}

\section{Self governing hospitals}

\author{
Ray Robinson
}

The devolution of decision making to the local operational level is one of the government's main objectives for the NHS. This is expected to secure local commitment; to produce services that are more responsive to the needs of patients; and to achieve greater value for money.' Encouraging the establishment of self governing hospitals is a key component of the policy designed to meet these aims.

Self governing hospitals will operate as independent trusts within the NHS. Each trust will be run by a board of directors with the chairman appointed by the Secretary of State. The board will be responsible for determining overall policy, while day to day management will be the responsibility of the general manager. Trusts will derive their income from service contracts obtained from district health authorities, general practitioner budget holders, and private patients. The government views competition between trusts, other NHS hospitals, and private hospitals as a mechanism for increasing efficiency and patient choice.

Initially it is intended that trusts will be restricted to major short stay hospitals with over 250 beds, although eventually other hospitals are expected to become eligible for self governing status.

- The government has a flexible definition of a self governing hospital

- Self governing hospitals could offer a range of community based services as well as acute care

- There could be self governing community units

- Neighbouring hospitals offering complementary services could combine into a single self governing unit.

Most of the advantages expected to result from self government derive from the greater autonomy that hospitals will be given to manage their own affairs. As in the case of the government's privatisation programme greater freedom from centrally imposed restrictions and bureaucratic control is expected to improve management's performance. Two main areas where this will apply are employment policy and capital spending.

\section{Employment policy}

Self governing hospitals will be given the freedom to determine their own staffing levels, rates of pay, and conditions of service. This freedom will cover all categories of staff, including doctors and nurses. The white paper argues that it is particularly important that trusts should be able directly to employ their own consultants. In determining rates of pay they may find it convenient to adopt national agreements. Alternatively, they may opt for arrangements that suit their local labour market conditions. Clearly, the government intends to remove what it sees as restrictive practices on pay and employment and to encourage a far more competitive labour market. What consequences can be expected to result from these changes?

\section{... doctors can also expect to be affected by the emergence of salary differentials.}

Freedom to determine rates of pay will almost certainly result in the emergence of wage and salary differentials between hospitals. Hospitals that are successful in competition for service contracts will be able to offer higher rates of pay to attract good quality staff. Similarly, hospitals located in areas with tight labour markets will have more freedom to offer competitive wages and salaries. In some cases, of course, higher rates of pay will lead to higher unit costs and place hospitals at a relative disadvantage when bidding for service contracts. In other cases improvements in productivity at more efficient hospitals can be expected to offset higher rates of pay.

The ability to determine their own rates of pay will offer more flexibility and may work to the advantage of self governing hospitals, but it could have deleterious effects on staff recruitment and retention at other NHS hospitals. Nursing staff, for example, might be expected to respond to opportunities to earn better salaries in self governing hospitals, especially if salaries in other hospitals continue to be restricted by national pay agreements. Some NHS hospitals are already suffering from the loss of key nursing staff to the private sector in specialties such as intensive care and theatre nursing. Competition from self governing hospitals may well exacerbate this type of problem.

Doctors can also expect to be affected by the emergence of salary differentials. Apart from variations in rates of pay between hospitals there may well be greater variation within hospitals. Some specialties will hold more revenue generating potential than others. In a system of workload funding there will be an incentive to link salaries more closely to the income generated by individual doctors and specialties. How far and fast this process will develop is difficult to predict.

Similar uncertainties surround changes in conditions 
of service. The government intends that existing staff in hospitals that become self governing will have their present conditions of service protected. But this will constitute a major restriction on management's freedom over employment policy. As such there will be clear'advantages in maximising the rate at which new staff contracts are implemented. These are likely to be of fixed term duration. Indeed, instead of employing consultants directly there may be attractions in employing them on a subcontracted basis for defined workloads.

In addition to its impact on pay differentials greater freedom for individual hospitals to determine their rates of pay may also exert upward pressure on overall NHS spending levels. ${ }^{2}$. One of the great merits of the NHS - which became increasingly apparent to ministers during the review preceding the white paper - is its ability to contain total spending. Unlike most other countries the United Kingdom does not suffer from overall cost inflation. Far from it: according to many people costs are contained too effectively. A major reason for successful cost containment has been the monopoly power, of the government as a purchaser of health service labour. If hospital trusts are given freedom to determine their own rates of pay this monopoly will be eroded. Of course, the government will still be able to control total spending via the public expenditure planning process. But it will become susceptible to new pressures. Generally wage driftthat is, payments above nationally agreed rates - results in increased spending because higher earnings are not offset by reductions elsewhere. Moreover, some districts will find that they face higher prices for services from their local self governing hospitals - as a result of its higher salary levels - and that without adequate allowance for this price inflation in their cash allocations there will be a reduction in the volume of services that they are able to buy. This can be expected to be yet another source of calls for increased funding.

\section{Capital spending}

The other main freedom which is to be offered to self governing hospitals is the freedom to manage their capital stock. Trusts will be given the power to acquire and dispose of assets. They will be able to borrow funds for investment purposes either from the government or from private institutions, although this power will be subject to an annual financing limit. And they will be able to make operating surpluses that can be used to finance future investment projects. These additional freedoms - together with the decision to introduce a system of capital charges into the NHS-offer the scope for a more rational approach to capital decision making. Management attention will be focused on the use made of the NHS's substantial holdings of estate and capital assets. It should lead for the first time to consideration of the relative costs of capital and labour and to more thorough examination of their appropriate mix in providing services.

Set against these advantages there must be reservations about the impact of capital charges on those hospitals occupying expensive, inner city sitesespecially in London-and the extent to which limits on aggregate spending determined by the Treasury will continue to restrict managerial freedom.

\section{Quality of service}

Self government will offer hospitals greater freedom to determine their own objectives. Constraints on their activity will arise from various government imposed regulations and the need to attract service contracts within a competitive market. The government expects the latter constraint to encourage the cost effective provision of services as rival hospitals seek to offer competitive prices. There is always a danger, however, that efforts to control costs will lead to reductions in service quality. Market competition-where purchasers have only fixed budgets to spend-poses a particular threat. Interestingly, competition in the United States has had precisely the opposite effect. Research evidence suggests that it has led to an increase in quality. ${ }^{+}$But this is because in the absence of effective control on total costs hospitals have competed in terms of quality instead of price. Cash limits are likely to prevent this state of affairs occurring in the NHS.

\section{. . . many hospitals now seem more cautious about applying for self governing status as the pitfalls become more apparent.}

The possibility that service quality may be jeopardised by competition makes the government's decision to strengthen medical audit especially important. It is envisaged that by April 1991 each district health authority will have established a medical audit advisory committee. These will be chaired by a senior clinician and include representatives from the major specialties and general management. The committees will have a variety of functions including the production of annual reports. These will identify clinical performance over the previous year and point to areas where action is needed to improve quality or efficiency in the future.

The proposal to strengthen and extend systems of medical audit has generally been welcomed. But questions still persist as to whether it will be sufficient on its own to ensure acceptable standards in the new competitive environment. Audit is a system of peer review. It is, in essence, self regulation by the providers of health care. Many people, including the National Association of Health Authorities, ${ }^{5}$ are unhappy with this. They have argued that monitoring should be carried out by an independent body such as an accreditation agency or an NHS inspectorate. Ministers, however, have rejected these suggestions.

\section{Local service provision}

Self governing hospitals are expected to secure local commitment and to offer services that are more responsive to their patients' needs. Yet concerns have been expressed that they may sever links with the local community and undermine attempts to provide a comprehensive range of services for local patients. The spectre has been raised of glamorous teaching hospitals offering high technology medicine to a national or international clientele while the needs of the local population suffering from chronic sickness are neglected. In fact, the white paper states quite clearly that core services will have to be provided locally to guarantee local access. Community based services, including those for elderly or mentally ill people, are mentioned as examples of these services. It is unlikely that the Secretary of State would permit a self governing hospital to refuse to enter into a service contract for the provision of such services if there was no adequate alternative in the locality.

Claims that hospital trusts will mean a reversion to the pre-1948, two tier system of voluntary and local authority hospitals are surely exaggerated. None the less, there may well be threats to comprehensive local provision at the margins. When decisions about the most cost effective or profitable use of individual beds are made by managers financial considerations may 
well provide incentives that act against the interests of some non-remunerative local services. To avoid this danger monitoring should extend beyond clinical outcomes and incorporate more general data on the comprehensiveness of services and access to them.

\section{Conclusion}

Self governing hospitals will represent an untried form of organisation operating within an untested market environment. It is impossible to say with any certainty how they or the market will perform. This will become clear only if and when the new style NHS gets under way. Recognition of the uncertainty surrounding these and other proposals led to widespread calls for experiments in the period of debate leading up to the publication of the white paper. But ministers have rejected this option. The white paper is about implementation not experimentation. Fortunately, however, the conditions that the government has specified as a prerequisite for attaining self governing status will mean that the pace of implementation can be only gradual. Indeed, after much initial enthusiasm many hospitals now seem more cautious about applying for self governing status as the pitfalls become more apparent. Present indications suggest that there is unlikely to be a rush of volunteers. All of this should mean that the process of implementation will at least provide the opportunity to learn by doing and to adjust the model of a hospital trust as its strengths and weaknesses become apparent.

1 Secretaries of State for Health, Wales, Northern Ireland, and Scotland. Self governing hospitals, Working paper I. London: HMSO, 1989. governing hospitals, Working paper I. London: HMSO, 1989. 2 Barr N, Glennester $\mathrm{H}$, Le Grand J. Working for patients? The right approuch London: London School of Economics, 1989.

3 Robinson R. New health care market. Br.Med f 1989;298:437-9.

4 Pauly M. Efficiency, equity and costs in the US health care system. In: American health care: what are the lessons for Britain? London: Institute of Economic Affairs, 1989.

5 National Association of Health Authorities. Working for patients. NAHA response to the House of Commons Social Services Committee. Birmingham: NAHA, 1989.

\title{
The white paper and the independent sector: scope for growth and restructuring
}

\author{
William Laing
}

Working for Patients ${ }^{1}$ has been enthusiastically received by independent sector interests. The NHS is to remain tax funded and this will be a disappointment to some diehards - though not an unexpected one. But any disappointment on this score is overshadowed by far by the prospect of private health care providers gaining access to what has hitherto been a largely closed NHS market. The white paper for the first time raises the real prospect of a single market for the delivery of publicly funded health care services, with public, charitable, and private suppliers competing on equal terms.

Exactly where the reforms will lead is hard to predict, since what is proposed is not so much a blueprint, like previous appointed day reforms, but rather a new framework for competition with al the uncertainty that entails. I can envisage greatly expanded private supply in some sectors. But equally there are real threats to the independent sector as currently constituted. I shall look at what the white paper might mean for the acute independent sector, firstly, in its traditional market - that is, privately paid or insurance funded services-and, secondly, in the new market that seems to be opening up, the NHS itself. In the absence of any white paper proposals on long stay and community care this important aspect of private sector activity is not covered.

\section{Privately funded short stay health care}

Medical insurance has been the engine of independent sector growth since 1948, accounting for $70 \%$ of the independent hospital revenue. The white paper proposes tax relief on medical insurance for people over 60 . This is the measure that seems to carry least conviction among ministers at the Department of Health. Put in at the insistence of the Prime Minister, it has been dismissed in private as incidental to the main thrust of the NHS reforms. But what will its impact be? My own view is not very much. I base this on analysis of past trends. The figure shows that rates of medical insurance growth are only moderately responsive to price. People over 60 who pay tax, or family members buying insurance for them, will normally find their medical insurance premiums reduced by $25 \%$ and coverage can be expected to rise by somewhat less than $25 \%$. Since people over 60 now make up a fairly small proportion of the medically insured population the new tax incentives are unlikely to make a substantial difference to the overall size of the medical insurance market. If, however, tax relief were to be extended to other age groups as well the impact would be that much greater. But as things stand those who dismiss tax relief for elderly people as a minor aspect of the white paper are probably right.

Tax relief will give an immediate if small fillip to medical insurance. But what will happen to the market in the longer term if the government's programme of NHS reform actually works? It would be wrong to characterise the growth of medical insurance cover as simply a manifestation of disillusionment with the NHS. Nevertheless, the most potent reason for taking out medical insurance is to avoid queues for NHS treatment. The state of the NHS waiting list at the time of the next election will be one of the key tests of success and there can be no doubt that the Department of Health will be trying its hardest to get this right. The NHS hospital trusts are going to play a crucial role

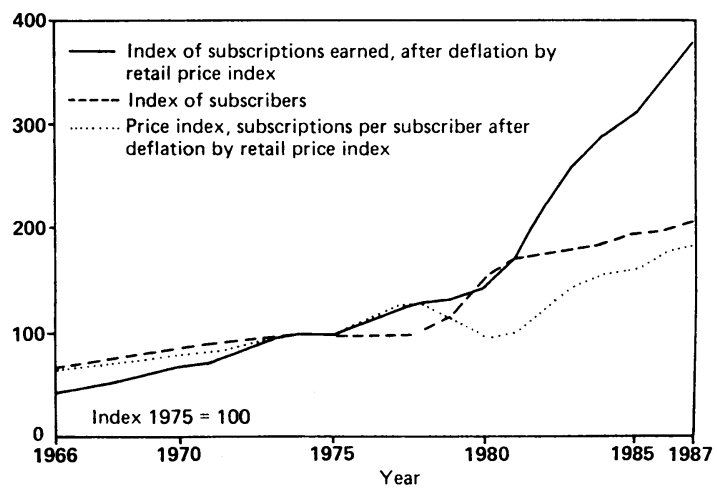

Medical insurance trends at constant prices after deflation by the retail price index, British United Provident Association, Private Patients Plan, and Western Provident Association data, 1966-87
1 Perren Street, London NW5 3ED.

$\operatorname{BrMed} \mathcal{f} 1989 ; 298: 821-3$ 